\title{
Marxismo e Serviço Social: mediações e contradições entre teoria e prática
}

\author{
Marxism and Social Work: mediations and contradictions between theory and practice
}

\section{Henrique Wellen*}

Resumo: A assimilação da teoria marxista pelo Serviço Social serviu para fortalecer a apreensão de seu locus operacional e revelar nuances contraditórias imanentes à profissão. Como expressão das contradições entre teoria e prática que fundamenta a profissão, destaca-se o sincretismo que se apresenta, intelectualmente, a partir de ecletismos teórico-metodológicos. Com o objetivo de aprofundar a análise desse fenômeno, buscou-se indicar a determinação imanente à reprodução do capital com base na relação de compra e uso da força de trabalho e que pressupõe uma imposição contraditória entre igualdade e desigualdade. Nesse sentido, no capitalismo, a defesa dos direitos sociais e das políticas sociais é combinada com a subsunção da força de trabalho, tanto pela necessidade de controle quanto pelo imperativo da produção e da acumulação de valor econômico.

Palavras-chaves: Serviço Social. Marxismo. Sincretismo - Teoria. Prática.

\begin{abstract}
The assimilation of Marxist theory by Social Services served to strengthen the capturing of its operational locus and reveal the contradictory nuances inherent to the profession. As a means of expressing the contradictions between theory and practice that underlie the profession, we highlight the syncretism that presents, intellectually, from theoretical and methodological eclecticism. Aiming to deepen the analysis of this phenomenon, the article seeks to identify the determination inherent to the reproduction of capital based on the relationship of purchase and use of the labour force and which presupposes a contradictory imposition between equality and inequality. In this sense, within capitalism, the defence of social rights and social policies is combined with the subsumption of the labour force, driven as much by the need for control as by the imperatives of production and the accumulation of economic value.
\end{abstract}

Key words: Social Service. Marxism. Syncretism - Theory. Practice.

Submetido em: 15/4/2018. Aceito em: 4/7/2018.

\section{INTRODUÇÃO}

A pesar da acepção historicamente recente acerca da caracterização do Serviço Social enquanto área de conhecimento, muitos movimentos políticos, metodológicos, acadêmicos e científicos demarcaram o robustecimento dessa dinâmica, seja no reconhecimento das agências brasileiras de fomento à pesquisa (especialmente, de caráter nacional, o CNPq e a CAPES), seja pelo desenvolvimento de um espaço de pesquisas dentro da ABEPSS, ou, ainda, pelos gradativos exemplares de pesquisas realizadas nas pósgraduações desses cursos (SPOSATI, 2007). Contudo, longe de instaurar-se pela primazia da formulação teórica sobre as práticas profissionais que, de forma direta ou não, carrega, dentro da divisão sócio técnica do trabalho, a subsunção da esfera da execução pelo complexo da concepção, o que se objetiva é um processo dialético entre as dimensões da produção

\footnotetext{
* Doutor em Serviço Social pela UFRJ. Professor do Departamento de Serviço Social da Universidade Federal do Rio Grande do Norte. (UFRN, Natal, Brasil). Av. Hermes da Fonseca, s/n, Lagoa Nova, Natal (RN), CEP.: 59084-10o. E-mail: <harw@uol.com.br>. ORC ID: <https://orcid.org/oooo-0o 02-47 87-5918>.
} 
intelectual e da ação prático-operativa. É nesse sentido que se dá a afirmação de Motta (2013), para quem o reconhecimento do Serviço Social “[...] como profissão e área de conhecimento [...]” (MOTTA, 2013, p. 19) não deve ser visto pela hierarquização entre concepção e execução, mas como uma relação entre as duas dimensões que, mesmo possuindo legalidades próprias, se consubstanciam no interior dessa categoria profissional.

A relevância situada nesse caráter epistêmico pode ser analisada tanto pelo necessário esforço de aprofundamento das incursões teóricas e metodológicas como pela precisão das mediações e legalidades específicas dessa dinâmica cognitiva. A realidade concreta que envolve o Serviço Social, por ser uma síntese de múltiplas determinações, possui indicações analíticas distintas que, a depender da perspectiva adotada, pode ser apreendida de forma mais profunda ou não. Isso porque, justamente por expressar essa multiplicidade de determinações, a realidade concreta aparece, inicialmente, a partir do reflexo cognitivo, como um resultado dado e, dessa forma, escamoteiam-se as nuances que consubstanciam a essência do objeto analisado. O esforço epistêmico dentro do Serviço Social, longe de situar-se em uma posição autônoma, que suspende intelectivamente a realidade social que a consubstancia, centra-se na análise profunda da essência desse objeto concreto. É a partir desse recurso que se pode apreender, dentre outros elementos, os limites e as possibilidades do Serviço Social a partir das determinações que incidem sobre essa categoria profissional. Nesse sentido, se a análise de um determinado contexto histórico, especificamente o desenvolvimento do capitalismo monopolista, é central para apontar para a constituição profissional do Serviço Social, o exame da mediação entre o desenvolvimento desse modo de produção - nas suas particularidades presentes em cada país - e o corpo interno (prático e teórico) que constrói essa categoria profissional, serve para indicar variadas disputas e embates.

\section{SERVIÇO SOCIAL, QUESTÃO SOCIAL E SINCRETISMO}

Nas fases inicias da constituição dessa categoria interventiva recaíam, sobre a função profi ssional dos Assistentes Sociais, arestas e fronteiras modelares de execução de políticas sociais ou, nos termos de Netto (1996), “[...] como um dos agentes executores das políticas sociais” (NETTO, 1996, p. 37). No entanto, o desenvolvimento econômico e social do capitalismo, somado à maturação teórica, interventiva e política da categoria profissional, produziu um alargamento desses limites, em aproximação aos espaços da concepção das políticas sociais. Dessa forma, conforme afirma Iamamoto (2005), se o “[...] Assistente Social tem sido historicamente um dos agentes profissionais que implementam políticas sociais, especialmente políticas públicas [...]" (IAMAMOTO, 2005, p. 20-21), com essa dinâmica social, assume, “[...] além de um trabalho na esfera da execução, a formulação de políticas públicas e a gestão de políticas sociais" (IAMAMOTO, 2005, p. 20-21, grifos do autor).

Ao apontar para uma incorporação de fundamentos analíticos que objetivavam analisar o modo de produção capitalista a partir da sua contradição fulcral, Netto (1996) expôs alguns impactos desse movimento no interior do próprio Serviço Social. A assimilação da teoria marxista não passou incólume à profissão e, se, por um lado, robusteceu a capacidade analítica acerca da apreensão do lócus operacional da profissão, por outro lado, revelou nuances contraditórias imanentes ao próprio interior da profissão. Nesse sentido, nas palavras do autor citado, 
O sincretismo nos parece ser o fio condutor da afirmação e do desenvolvimento do Serviço Social como profissão seu núcleo organizativo e sua norma de atuação. Expressase em todas as manifestações da prática profissional e revela-se em todas as intervenções do agente profissional como tal. O sincretismo foi um princípio constitutivo do Serviço Social (NETTO, 1996, p. 88, grifos do autor).

Assim, ao apreender a relação entre a questão social, as políticas sociais e a constituição do papel do Assistente Social, ficaria patente, para o autor, a existência de um sincretismo que consubstanciaria a profissão. Não obstante, ainda que um reflexo mais imediato desse si ncretismo se apresentasse na presença de ecletismos teóricos e metodológicos, a superação de tal amálgama intelectiva não necessariamente superaria esse fenômeno que, a seu ver, seria imanente à profissão. Como não é a consciência social que, autonomamente, determina a existência social, e como o peso maior das determinações ontológicas se encontra nesse sentido oposto, poder-se-ia perguntar se o Serviço Social, dentro do modo de produção capitalista, sempre carregaria a qualidade sincrética.

A relevância atual dessa questão não se encontra na inferência profética acerca de movimentos contraditórios do porvir. Distante de elucubrações de teor valorativos, podem-se vislumbrar duas dinâmicas analíticas concretas. A primeira indica que a presença do si ncretismo precisa ser analisada de forma dialética e, dessa forma, se, de um lado, isso demonstra limites da profissão, por outro lado, também demonstra possibilidades e alternativas concretas. Não somente a consciência acerca desse sincretismo só pode ser radicalmente apreendida a partir da adoção de uma perspectiva crítica como, inversamente, é a assimilação e o desenvolvimento de análises marxistas que pode ampliar o grau desse sincretismo. A análise do sincretismo remete a uma contradição entre dois polos adversos que, no caso do Serviço Social brasileiro, se constitui, de um lado, pela funcionalidade perante a vigência do atual ordenamento societário e, do outro, pela hegemonia teórica e política marxista. A contradição da contradição é que, quanto mais o ponteiro, que demarca a gradação dessa dinâmica, se aproxima desse lado, mais explicitamente visualiza-se o sincretismo. Ou seja, quanto mais tensões existirem entre esses polos, mais a presença do sincretismo será explicitada.

Como indicação da presença desse paradoxo que lastreia o sincretismo, serve um contraponto teórico e político. Podem-se citar as seguintes palavras de Quintaneiro (1995), ao analisar o pensamento de Durkheim (2007) acerca dos distúrbios presentes em torno da conservação da sociedade:

Quanto mais extensa é a consciência coletiva, mais a coesão entre os participantes da sociedade examinada refere-se a uma "conformidade de todas as consciências particulares a um tipo comum”, o que faz com que todas se assemelhem e, por isso, os membros do grupo sintam-se atraídos pelas similitudes uns com os outros, ao mesmo tempo em que a sua individualidade é menor (QUINTANEIRO, 1995, p. 78).

Para o sociólogo francês, para se instaurar uma dinâmica conservadora da sociedade, far-seia necessário que os distúrbios sociais fossem aplacados por imperativos morais (representados por fatos sociais) que, a seu ver, deveriam operar numa analogia com a legalidade natural (cf. Durkheim, 2007). E, para tanto, quanto menos resistência existisse em torno da subsunção dos indivíduos a essas entidades morais, mais a sociedade alcançaria a sua estabilidade ou, nos seus termos, a coesão social. A centralidade atribuída à coesão social expressa,

Argum., Vitória, v. 10, n. 2, p. 122-134, maio/ago. 2018. 
por sua vez, uma intencionalidade de uma "[...] reprodução ideológica da sociedade pela via da moral [...]" (GUERRA, 2005, p. 64-65) que, de forma direta ou não, aponta para uma despolitização da análise e da intervenção sobre a questão social. Seguindo estas premissas positivistas, quanto menos distensão entre indivíduos e fatos sociais, maior seria a coesão social e, portanto, mais estáveis seriam as regras sociais. Destarte, a questão social, no lugar de refletir uma contradição entre capital e trabalho, seria analisada e instrumentalizada pela categoria da moral.

A análise de outra indicação do sociólogo francês também contribui para apreender algumas nuances do sincretismo apontado. Trata-se da forma como Durkheim (1975) concebe a relação entre teoria e prática, uma vez que, a seu ver, "[...] a ciência só aparece quando o espírito, abstraindo toda a preocupação prática, aborda as coisas com o único fim de ter representações delas" (DURKHEIM, 1975, p. 104). O parâmetro para a construção do conhecimento científico se radicaria, assim, no distanciamento das intencionalidades e das necessidades práticas, se direcionando para um dualismo entre a teoria e a prática. Inserindo essa premissa dentro da obra do autor e, em especial, a partir das suas convicções políticas, não seria ousado admitir que, no fundo, esse dualismo carrega uma valoração política de cunho claramente conservador (cf. WELLEN; CARLI, 2016).

A segunda dinâmica analítica concreta acerca do sincretismo remete para a forma como se processa, dentro da constituição teórica e metodológica, a relação da apreensão da questão social e a sua mediação com a conexão entre teoria e prática. Isso porque, a depender da perspectiva teórica e metodológica adotada, tanto a análise da questão social como a relação entre teoria e prática podem ser apreendidas de formas bastante distintas. No caso em tela do Serviço Social brasileiro - foi a incorporação de autores e categorias integrantes da tradição marxista que lastreou um movimento de análises e de intervenções acentuadamente críticas tanto à ordem societária vigente, quanto à relação dos Assistentes Sociais com as refrações da questão social (NETTO, 1989). A teoria não intervém no mundo, mas, quando utilizada de forma massiva, serve de conteúdo essencial para isso.

É fato que o sincretismo opera a partir de disputas e amálgamas entre concepções de mundo acerca da relação entre teoria e prática. Mas, ainda que esse fenômeno se expresse através da ideologia, ele não pode ser analisado endogenamente nesse complexo social. O sincretismo é uma fusão contraditória de perspectivas e concepções ideológicas, mas esses antagonismos não são criados internamente (pois, se assim o fosse, estar-se-ia subscrevendo o citado pensador positivista em relação ao fato social como imperativo moral fundante da sociedade). Assim, se é importante um resgate ontológico no seu método de análise (SOUZA, 2016), fazse necessário voltar-se para o seu lastro constitutivo, localizado nas contradições dentro do capitalismo. Por seu turno, tais contradições, de ordens complementares e dialéticas, expressam-se inicialmente na esfera produtiva e, depois, a partir de variadas mediações e especificidades, pautam-se no campo ideológico e, dentro desse, nas esferas política e teóricometodológica.

É por demais conhecido o debate acerca da base constitutiva da profissão do Serviço Social, especialmente no tocante às mediações e contradições teóricas e práticas entre a indicação da questão social e a das políticas sociais. Se, por um lado, a busca por essa precisão analítica contribui diretamente para apontar limites e possibilidades presentes na relação entre teoria

Argum., Vitória, v. 10, n. 2, p. 122-134, maio/ago. 2018. 
e prática do Assistente Social, por outro lado, essa contenta termina por escamotear um elemento de grande relevância analítica. Dentro do capitalismo, a questão social se estabel eceu, de forma gradativa, pela sua relação com a constituição e vigência das políticas sociais. Da mesma forma, as políticas sociais, dentro dos limites desse modo de produção, existem também para responder às contradições da questão social. Se, sem uma relação contratual baseada em troca de valores econômicos não existe mercado capitalista e, portanto, não existe possibilidade de exploração da mais-valia; se, sem o Estado, não existe a possibilidade do capital operar no seu ciclo de reprodução ampliada; se as políticas sociais são uma determinação, ao fim e ao cabo, que se remete à reprodução da força de trabalho; a questão social, nesse sentido, é fundamento e fundamentada pelas políticas sociais. Vejamos algumas indicações acerca dessa contraditória dinâmica.

\section{DIREITOS E EXPLORAÇÃO: MEDIAÇÕES E CONTRADIÇÕES ENTRE TEORIA E PRÁTICA}

Diferentemente dos modos de produção anteriores, o capitalismo demandou a instauração de uma determinada igualdade entre as pessoas. Esse movimento, contudo, ainda que tenha expressado um papel revolucionário, não pode ser dissociado do seu anverso de exploração (MARX; ENGELS, 2010). O estabelecimento de uma forma mais avançada e concentradora de exploração do trabalho exigiu uma nova mediação social que, contraditoriamente, fomentou laços de igualdade entre as pessoas. Conforme indicou Lukács (2013), “[...] somente com o surgimento e a intensificação do mercado mundial é que o gênero humano foi posto na ordem do dia como problema geral e que engloba todos os homens" LUKÁCS, 2013, p. 128). Uma das principais especificidades econômicas do modo de produção capitalista, que o diferencia de modos de produção anteriores, encontra-se no escopo da sua dominação econômica.

De forma tautológica, é somente no capitalismo que o capital conseguiu dominar todas as esferas econômicas, se apropriando dos meios de produção e da esfera produtiva:

O modo de produção capitalista é o primeiro modo de produção, a primeira forma de organização social, na qual o capital já não desempenha simplesmente o papel de intermediário e de explorador de formas de produção não capitalistas que continuam alicerçadas na pequena produção mercantil, mas nos quais o capital se apropriou dos meios de produção e penetrou na produção propriamente dita (MANDEL, 1978, p. 43).

Foi a partir do desenvolvimento do mercado e da vigência do modo de produção capitalista que as relações de trocas se ampliaram tanto que determinaram a centralidade das mercadorias nas mediações sociais. O capitalismo é, portanto, “[...] a primeira sociedade da história humana na qual a maior parte da produção é composta de mercadorias” (MANDEL, 1978, p. 9). Assim, estando a produção social fundada e direcionada pelas mercadorias, não é a forma ou a qualidade do uso destes produtos que será determinante, mas sim o valor econômico proveniente da sua aquisição. Isto, porque, "[...] para se tornar uma mercadoria, um produto precisa ser transferido, por meio da troca, para outro, a quem ela servirá como valor de uso" (MARX, 2010b, p. 51). Com a expressão do valor de troca dominando as relações econômicas, duas determinações acompanham o processo capitalista: a produção e a compra das mercadorias. E, sendo representadas pelo valor de troca, não apenas a utilidade das mercadorias

Argum., Vitória, v. 10, n. 2, p. 122-134, maio/ago. 2018. 
fica subsumida nesse processo produtivo, como o mesmo ocorre com a funcionalidade dos seus produtores. Estando ambos inseridos no mercado capitalista, ambos operam como mercadorias. Todavia, sendo assim determinados, resta uma questão: quais os parâmetros reguladores das relações de compra e venda das mercadorias?

Usar o tempo despendido na produção como critério para medir o valor dos produtos que estavam sendo trocados, teve, no capitalismo, um grande desenvolvimento. A relação de troca de mercadorias pôs, historicamente, a necessidade de se conhecer a medida dos seus valores. Além disso, é escusado dizer que, nessa relação de troca, as duas partes envolvidas estão buscando o mesmo objetivo. Consequentemente, trata-se também de analisar a possiblidade da equivalência nessa mediação econômica:

É a expressão de equivalência entre diferentes tipos de mercadorias que, por si mesma, traz à tona o caráter específico do trabalho criador de valor, e isso se faz, na verdade, através da redução de diferentes variedades de trabalho, incorporados nos diferentes tipos de mercadorias, à sua qualidade comum de trabalho humano abstrato (MARX, 2010b, p. 61).

A partir da representação geral do valor de troca nas relações do mercado, o confronto entre as mercadorias se expressou, também, pelo confronto de diferentes dispêndios de atividades humanas. Nessa relação, o tempo de trabalho dispendido na produção das mercadorias trocadas configura-se pela conexão entre diferentes trabalhos privados e pela abstração dessas atividades numa simples "[...] gelatina de trabalho humano" (MARX, 1996, p. 179). Com a vigência do valor de troca nas relações econômicas, deixam-se de lado as especificidades de cada trabalho realizado e os seus caráteres de utilidade, restando, simplesmente, o trabalho humano no seu sentido abstrato (cf. MARX, 2010b). A quantidade de força de trabalho dispendida como determinação do valor das mercadorias além de expressar uma possibilidade de medida de equivalência entre as trocas, também pressupõe uma determinação produtiva social. Como se tratam de valores equivalentes de mercadorias, tal equivalência encontra-se pressuposta nos diferentes tipos de trabalhos. Por isso, não se trata de valores de trabalhos individuais, mas da relação social destes com o desenvolvimento geral das forças produtivas. De forma breve, é dessa análise que se sobressai a categoria de trabalho socialmente necessário (MARX, 2010b).

Tal dinâmica também produz incidências metodológicas, uma vez que, para conseguir anal isar esse movimento, requer-se uma visão de totalidade. Além das conexões sociais entre os diferentes tipos de trabalhos, conduzindo à apreensão da categoria do trabalho abstrato, também se faz necessária uma abstração metodológica. Se a existência das mercadorias já pressupõe uma determinação social, o aferimento do seu valor só se faz possível a partir das suas conexões com o desenvolvimento social (cf. HEINRICH, 2004). Isto porque, conforme afirma Marx (2010b), o valor das mercadorias é, por suposto, uma determinação puramente social. Essa qualidade puramente social determinando o seu valor indica uma suspensão das qualidades naturais presentes nas mercadorias, como o peso, o tamanho ou a idade. Além disso, esse tipo específico de valor, que remete à quantidade de trabalho invertido na mer-

\footnotetext{
${ }^{1}$ Ressalta-se a existência de diferenças nas traduções para esse termo. Em diversos momentos, consta, na tradução inglesa (MARX, 2010b), o seu uso como "congelação de trabalho humano" (congelation of human labour), enquanto que, na versão original alemã (MARX, 1962), se aproxima de "geleia de trabalho humano" (Gallerte menschlicher Arbeit).
}

Argum., Vitória, v. 10, n. 2, p. 122-134, maio/ago. 2018. 
cadoria, precisa ser calculado a partir de um quantum social. Não se trata desse ou daquele trabalho realizado, mas da média social destes trabalhos, expressos na quantidade média necessária para a produção deste tipo de mercadoria. Entretanto, se o valor da mercadoria é determinado pela quantidade de trabalho que nela foi dispendida, qual o valor do próprio trabalho e o que determina essa medida?

Diferentemente de Adam Smith ou de David Ricardo (dois dos maiores pensadores dessa área de conhecimento e bastante admirados por Marx) que, diretamente ou não, terminaram por criar circunlóquios nessa relação, o autor de $O$ Capital elucidou, de forma objetiva e precisa, essa dinâmica capitalista. Se os valores das mercadorias são medidos pela quantidade de força de trabalho nelas dispendidas, o mesmo deve ser aplicado para aferir o valor da própria força de trabalho. Como expressão do valor da força de trabalho, o que o salário representa não é aquilo que o trabalhador produziu durante o tempo em que ficou na empresa, mas sim aquilo que, em média, foi necessário para manter a sua subsistência. Para o que nos interessa aqui, o valor da força de trabalho não exprime o valor resultante do uso desta mercadoria, mas, antes, significa o valor para a sua reprodução que, enquanto expressão monetária, chama-se salário. O salário pago pelo capitalista ao trabalhador não representa aquilo que o trabalhador produziu durante o tempo em que ficou ao seu serviço, mas tão somente aquilo que se destinou à sua manutenção.

Na esfera da circulação econômica, essa relação aparece como uma simples troca de mercadorias: a venda e a compra da força de trabalho e, por isso, trata-se de um intercâmbio de valores equivalentes. Contudo, o mesmo não se apresenta na esfera da produção. Tanto o trabalhador, como o capitalista, aparecem, dentro do mercado capitalista, como dois indivíduos portadores de mercadorias que são trocadas livremente e igualmente. Um tem algo para vender e quer algo em troca e o outro deseja algo para comprar e precisa, portanto, repassar algo em troca. A força de trabalho é trocada por um salário. Por outro lado, quando se analisa o uso que foi feito dessa força de trabalho dentro do processo produtivo, o valor que foi produzido pelo trabalhador se dissocia daquele que lhe foi dado em troca da compra da sua força de trabalho. Nessa dinâmica, como o salário não representa aquilo que o trabalhador produziu, o resultado proveniente do uso da sua capacidade produtiva também não lhe pertence. Destarte, caso o valor resultante desse processo seja superior àquele que lhe foi pago como salário, ele será de propriedade do capitalista. E, no fundo, o capitalista só irá comprar essa mercadoria (a força de trabalho) se ela lhe tiver essa serventia. Surge, portanto, uma diferença econômica entre o valor da força de trabalho e o valor criado pela força de trabalho. Ao indicar a existência da mais-valia, Marx (2010b) terminou por apresentar a dialética da conjugação de uma relação de equivalências com uma relação de nãoequivalências.

Na imanência dessa relação entre equivalente e não equivalentes destaca-se um elemento que se refere à legitimidade desse contrato aceito de "livre vontade" entre as duas partes. A legitimação da relação de equivalência de trocas dos valores das mercadorias na esfera da circulação serve de base para a legitimação da não-equivalência entre os valores relacionados na esfera da produção de mercadorias. E, como se trata de legitimação, a instituição que fundamenta a constituição do Serviço Social como profissão tem, aqui, uma presença determinante. As seguintes palavras de Teixeira (1999) são esclarecedoras acerca das mediações e das contradições dessa relação:

Argum., Vitória, v. 10, n. 2, p. 122-134, maio/ago. 2018. 
[...] como numa mesma relação de troca podem subsistir dois princípios imediatamente contrários: o de equivalência e o de não-equivalência? A resposta agora se torna clara: o princípio da equivalência vige quando as trocas são apreendidas como atos entre indivíduos; o da não-equivalência, que na verdade é uma não-troca, quando se considera o processo capitalista no fluxo ininterrupto de sua renovação; ou seja, quando se passa do mundo da experiência vivida pelos indivíduos para o das classes sociais. Por conta disto, instaura-se uma contradição entre o mundo da aparência e o da essência do sistema.

Porque contraditória, essa relação entre essência e aparência não pode ser abandonada a si própria; ela exige uma forma social para se desenvolver e realizar-se. Esta forma é o Estado. Sua função é zelar e fazer valer, através da lei, o desenvolvimento das relações de troca entre capitalistas e trabalhadores, que se operam através de uma série de contratos jurídicos privados. Enquanto guardião dessas relações de troca, o Estado considera os indivíduos como nômades e, assim, detentores de direitos iguais, porque fundados no princípio da troca de equivalente (TEIXEIRA, 1999, p. 106).

O aparato jurídico presente nessa relação tem uma importância fundamental e, ao mesmo tempo, paradoxal. Serve tanto para legitimar uma relação de trocas de equivalentes como para naturalizar uma relação de exploração. O Estado capitalista, na qualidade de provedor e mantenedor de direitos iguais, toma por pressuposto uma relação entre equivalência entre os indivíduos. Na aparência econômica da circulação de mercadorias, vislumbram-se dois polos equivalentes de trocas individuais de mercadorias e que, portanto, precisam de direitos iguais para assegurar a sua propriedade econômica. Por outro lado, essa relação entre indivíduos portadores de direitos iguais esbarra na relação de classes imanente à estrutura produtiva capitalista. A existência da exploração contradiz a possibilidade de uma relação de equivalentes e também expressa os indivíduos pelo seu pertencimento econômico de classe. Mesmo sob a alcunha de direitos sociais, a centralidade burguesa se estabelece pela visualização de uma relação entre indivíduos. Com o estabelecimento da força de trabalho como fundamento da produção econômica, as relações jurídicas capitalistas comportam uma contradição entre universalidade e individualismo. Diferentemente das sociedades a nteriores, no capitalismo não se explicita uma imposição classista do direito e esse se expõe numa relação de universalidade humana. Estando esta expressão jurídica derivada de uma relação de trocas de mercadorias entre indivíduos, a sua jurisdição, aparentemente, não comporta uma determinação de classe.

Contudo, se o Estado não atende diretamente aos interesses desta ou daquela classe, ele serve para conservar uma ordem que atende aos interesses desta ou daquela classe. A sua mediação não é diretamente com as classes, mas com a legitimação das regras da sociedade baseada na estrutura de classes. O tratamento político desconectado da propriedade privada também pressupõe e legitima a própria propriedade privada, uma vez que "[...] a anulação político da propriedade privada não somente falha em abolir a propriedade privada como também pressupõe a sua existência” (MARX, 2010a, p. 153). Por isso que, se, de um lado, constata-se a presença de uma igualdade formal entre os indivíduos, por outro lado, explicita-se a vigência de uma desigualdade real (PIVA, 2012). Ainda que se atendam aos interesses da classe burguesa, estes desígnios se encontram mediados pela manutenção da ordem social que, como vimos, conjuga-se pela relação de direitos e de exploração. Os assuntos e negócios comuns dessa classe se mantêm essencialmente pela preservação do mercado capitalista (cf. MARX; ENGELS, 2010), na sua relação de troca de equivalentes e não equivalentes. E o

Argum., Vitória, v. 10, n. 2, p. 122-134, maio/ago. 2018. 
limite dessa determinação se expressa, também, tanto nos direitos sociais como nas políticas sociais.

A contradição não se situa nem nas políticas sociais nem internamente na profissão do Assistente Social. Trata-se, antes, de uma contradição imanente à reprodução do capital como uma relação de compra e de uso da força de trabalho que pressupõe uma necessária imposição contraditória entre igualdade e desigualdade. E, dessa forma, os processos de subsunção da força de trabalho pelo capital pressupõem essa necessidade de controle do trabalhador que não pode ser explicitamente interna às classes dominantes, mas pela via de atuação de uma instituição aparentemente neutra - o Estado. Dentro da sociedade capitalista, a defesa dos direitos sociais e das políticas sociais conjuga-se com a subsunção da força de trabalho, tanto pela necessidade de controle como pelo imperativo da produção e da acumulação do valor econômico. Essa mediação do Estado com a força de trabalho não aparece como uma relação de classe, mas como uma regulação de direitos individuais. Se, conforme afirmou Faleiros (2016, p. 73), “[...] a população-alvo das políticas sociais não são os indivíduos isolados, mas a força de trabalho atual ou potencial” (FALEIROS, 2016, p. 73), essa relação de acesso e garantia dos direitos não se estabelece a partir de uma relação de classe. E, ainda que a "[...] correlação de forças sociais e o desenvolvimento do Estado democrático de direito [...]" (FALEIROS, 2016, p. 73, grifos do autor), sejam importantes para garantir os direitos sociais, isso não invalida a existência da desigualdade econômica.

No fundo, a análise da igualdade formal desvinculada da desigualdade real termina por conduzir a uma mistificação dos direitos e das políticas sociais presentes dentro do capitalismo ${ }^{2}$. Nesse sentido, o combate idealista ao sincretismo, quando deslocado das contradições estruturais do modo de produção capitalista, não apenas conecta-se a uma distorção analítica, mas redunda em efeitos ideológicos e políticos negativos ao processo de transformação social. O sincretismo não é somente reflexo da profissão ou das políticas sociais. Se expressa, antes, na distensão, imanente ao modo de produção capitalista, entre a necessária defesa do acesso e do uso de direitos sociais, com a preservação e a ampliação da exploração da força de trabalho. Se isso não inviabiliza nem um pouco a análise e a utilização desses complexos como forma de defesa da igualdade, também não se permite visualizar que serão as políticas sociais que colocarão fim à desigualdade.

\section{CONSIDERAÇÕES FINAIS}

A relação do Serviço Social brasileiro com movimentos políticos e sociais, sobretudo a partir de 1980, assim como com o incremento de pesquisas mais críticas, especialmente desenvolvidas nos espaços de pós-graduação desses cursos, constituiu um marco importante para a profissão. Com isso, operou-se tanto um deslocamento da base teórica metodológica hegemônica, como também uma impostação mais efetiva entre a análise teórica da realidade e a

\footnotetext{
2 Mesmo que a tendência atual seja de destituição dos direitos sociais e da relação entre as políticas sociais e a reprodução da força de trabalho, essa questão é fundamental para a análise. E, diante disso, caso essa tendência se confirme, a função das políticas sociais (ou a sua destruição) direciona-se tão somente para formas de repressão e de consenso, o que tornaria irreversível o papel interventor do Estado no processo de produção e acumulação capitalista, especialmente no tocanteà sua regulação universal na esfera das trocas de mercadorias, vislumbrando lhe apenas um horizonte de exceção social. E, sendo esse o caso, não se poderia mais falar em disputas de classes tencionando o Estado para realizar políticas sociais, mas apenas lutas de classes pela sua destruição.
}

Argum., Vitória, v. 10, n. 2, p. 122-134, maio/ago. 2018. 
capacitação interventiva e política. Nessa esteira, dois fatos podem ser elencados como emblemáticos dessa dinâmica: os efeitos cognitivos e intelectivos, e as tessituras técnicooperativas. E, se estas integraram uma ampliação do aporte e do escopo da profissão, aqueles se constituíram também pela assimilação e adoção de novos ingredientes analíticos. Assim, se, de um lado, tangenciou-se, no interior da profissão, um movimento de recolocação no espaço laboral, por outro lado, as categorias da tradição marxista tornaram-se, gradativamente, fermento de análises teóricas e de intervenções práticas.

Como anteriormente indicado, tal processo se revelou com maior profundidade na superação do escopo limitativo do Assistente Social enquanto um "[...] como um dos agentes executores das políticas sociais" (NETTO, 1996, p. 37). Destarte, operou-se tanto um incremento analítico na formação profissional, como esse se revelou, também a partir de constelações valorativas. Em outras palavras, a relação analítica entre a questão social e a teoria e a prát ica dos Assistentes Sociais, ao ser municiada através de chaves heurísticas relativas à tradição marxista, impactou tanto na perspectiva teórico e metodológica da categoria profissional, como também na constituição de novos condutores valorativos, especialmente expressos no código de ética e no projeto ético e político da profissão.

Nesse sentido, a conexão entre teoria e prática, centralmente na referência à prática profissional, recebeu novas mediações analíticas que, além de permitir uma apreensão mais complexa da profissão, também se deslindou na análise entre aparência e essência ou, em outros termos, entre a expressão fenomênica e a realidade concreta. Conforme indica lamamoto (2004), constatou-se que tanto "[...] a prática profissional não se revela na sua imediaticidade [...]" (IAMAMOTO, 2004, p. 117), como que a relação entre aparência e essência opera carregada de mediações, "[...] tornando-se necessário desvendar as próprias formas fenomênicas, como formas de expressão necessárias, gestadas na própria sociedade capitalista, para se apreender o núcleo da prática social" (IAMAMOTO, 2004, p. 117, grifos do autor). E, notadamente acerca dos condutores valorativos da profissão, a assimilação da tradição marxista operou um impacto significativo. Tal relevância pode ser constatada a partir da conexão política que se instaurou entre as demandas da classe trabalhadora e a formação profissional, conforme elucida Barroco (2004): a “[...] negação da 'neutralidade' profissional, registrada formalmente em 1986 através da afirmação do 'compromisso' com a 'classe trabalhadora', representou um marco fundamental no processo de ruptura com o conservadorismo profissional” (BARROCO, 2004, p. 188). Para tanto, no entendimento da autora, a consonância valorativa entre esses dois elementos se expressaria, com maior precisão, na compreensão da ética, uma vez que a “[...] sua principal função é a de estabelecer a crítica radical à moral do seu tempo, fornecendo elementos para a compreensão dos impedimentos à sua livre manifestação" (BARROCO, 2004, p. 193).

Não obstante, mesmo que esta capacidade analítica porte a mediação dialética entre políticas sociais, questão social e direitos sociais, a apreensão dos complexos meandros imanentes a essa relação não imiscui estes profissionais de contradições nas relações entre teoria e prática. A própria terminologia utilizada para indicar as intencionalidades desse processo crít ico - “[...] intenção de ruptura [...]" (NETTO, 2005a, p. 247) - já apontava, mesmo que de forma indireta, para esse movimento. Assim, se, de um lado, cogita-se um processo de superação do ecletismo teórico, por outro lado, do ponto de vista do exercício profissional, o sincretismo é um componente ineliminável, uma vez que se encontra “[...] conectado a instân-

Argum., Vitória, v. 10, n. 2, p. 122-134, maio/ago. 2018. 
cias e mediações que ultrapassam e circunscrevem a profissão" (SOUZA, 2014, p. 26). De toda forma, seja pela expressão teórico-metodológica, seja pela formação valorativa, existe, portanto, uma relação entre três elementos centrais para a análise do desenvolvimento do Serviço Social brasileiro: a questão social, a relação entre teoria e prática e a assimilação da tradição marxista. E, se é escusado afirmar que os destinos das duas tendências anteriores se encontram em aberto, configurando-se de forma subordinada ao desenrolar do devir histórico, da mesma forma, observa-se que uma análise que apreenda novos elementos dessa dinâmica pode carregar um relevo significativo tanto no seu caráter de pesquisa científica, como na sua mediação com os processos interventivos.

\section{REFERÊNCIAS}

BARROCO, Maria Lúcia Silva. Serviço Social, Ética e Direitos Humanos. Revista Praia Vermelha: estudos de política e teoria social, Rio de Janeiro, n. 11, p. 184-194, 2004.

DURKHEIM, Émile. As regras do método sociológico. 3. ed. São Paulo: Martins Fontes, 2007. (col. Tópicos).

DURKHEIM, Émile. A ciência social e a ação. São Paulo: Difel, 1975.

FALEIROS, Vicente de Paula. A política social do Estado Capitalista. 12. ed. São Paulo: Cortez, 2016.

GUERRA, Yolanda. A instrumentalidade do serviço social. 4. ed. São Paulo: Cortez, 2005.

HEINRICH, Michael. An Introduction to the Three Volumes of Karl Marx's Capital. New York: Monthly Review Press, 2004.

IAMAMOTO, Marilda. Renovação e Conservadorismo no Serviço Social: ensaios críticos. 7. ed. São Paulo: Cortez, 2004.

IAMAMOTO, Marilda. O Serviço Social na Contemporaneidade: trabalho e formação profissional. 8. ed. São Paulo: Cortez, 2005.

LUKÁCS, György. Para uma Ontologia do Ser Social. Vol. 2. São Paulo: Boitempo, 2013.

MANDEL, Ernest. Iniciação à Teoria Económica Marxista. 4. ed. Lisboa: Edições Antídoto, 1978 .

MARX, Karl. ENGELS, Friedrich. Manifesto of the Communist Party. In: MARX, Karl; ENGELS, Friedrich. Collected Work. Vol. 6. London: Lawrence \& Wishart, 2010.

MARX, Karl. On the Jewish Question. In: MARX, Karl; ENGELS, Friedrich. Collected Work. Vol.3. London: Lawrence \& Wishart, 2010a.

MARX, Karl. Capital: a Critique of Political Economy. v. I. In: MARX, Karl; ENGELS, Friedrich. Collected Work. Vol.35. London: Lawrence \& Wishart, 2010 b. 
MARX, Karl. O Capital: crítica da economia política. v. I, Livro Primeiro: o processo de produção do capital. Tomo I. São Paulo: Nova Cultural, 1996. (col. Os Economistas).

MARX, Karl. Das Kapital: Kritik der politischen Ökonomie. Erster Band, Buch I: Der Produktionsprozeß des Kapitals. In: MARX, Karl; ENGELS, Friedrich. Werke. Band 23. Berlim: Dietz Verlag, 1962.

MOTTA, Ana Elizabete. Serviço Social brasileiro: profissão e área de conhecimento.

Katálysis, Florianópolis, v. 16, p. 17-27, 2013.

NETTO, José Paulo. O Serviço Social e a tradição marxista. Revista Serviço Social \& Sociedade, São Paulo: Cortez, ano 10, n. 30, p. 89-102, maio/ago. 1989.

NETTO, José Paulo. Capitalismo monopolista e Serviço Social. 2. ed. São Paulo: Cortez, 1996.

NETTO, José Paulo. Ditadura e Serviço Social: uma análise do Serviço Social no Brasil pós64. 8. ed. São Paulo: Cortez, 2005.

PÍVA, A. Burocracía y Teoria Marxista del Estado. Intersticios: Revista Sociológica de Pensamiento Crítico, Buenos Aires, v. 6, n. 2, p. 27-48, 2012.

QUINTANEIRO, Tânia. Émile Durkheim. In: QUINTANEIRO, Tânia et al. Um toque de clássicos: Marx, Durkheim e Weber. 2. ed. Belo Horizonte: UFMG, 1995.

SPOSATI, Adaílza. Pesquisa e produção de conhecimento no campo do Serviço Social. Katálysis, Florianópolis, v. 10, p. 15-25, 2007.

SOUZA, Jamerson Murillo Anunciação de. Três notas sobre o sincretismo no Serviço Social. Serviço Social e Sociedade, São Paulo, n. 119, p. 531-559, 2014.

SOUZA, Jamerson Murillo Anunciação de. Tendências Ideológicas do Conservadorismo. 2016. Tese (Doutorado em Serviço Social)-Programa de Pós-Graduação em Serviço Social, Universidade Federal de Pernambuco, Recife, 2016.

TEIXEIRA, Francisco José S. Sobre a crítica dialética de O Capital: uma anticrítica. Revista Crítica Marxista, São Paulo, n. 8, p. 93-115, 1999.

WELLEN, Henrique; CARLI, Ranieri. Serviço Social e a relação entre teoria e prática. In: MOTA, Ana Elizabete; AMARAL, Angela (Orgs.). Cenários, Contradições e Pelejas no Serviço Social Brasileiro. São Paulo: Cortez, 2016. 


\section{Henrique WELLEN}

Graduado em Administração de Empresas e em Administração Pública pela UFPB. Mestre em Gestão e Políticas Públicas na UFRN. Doutor em Serviço Social pela UFRJ. Professor do Departamento de Serviço Social da UFRN.

Argum., Vitória, v. 10, n. 2, p. 122-134, maio/ago. 2018. 